\title{
New ARCHITECT plasma pro-gastrin-releasing peptide assay for diagnosing and monitoring small-cell lung cancer
}

\author{
Benjamin Nisman ${ }^{\star}, 1,5$, Hovav Nechushtan ${ }^{1,5}$, Haim Biran², Nir Peled ${ }^{2}$, Hadas Gantz-Sorotsky ${ }^{1}$, \\ Victoria Doviner ${ }^{3}$, Marina Perelman ${ }^{4}$, Jair Bar ${ }^{2}$, Amir Onn $^{2}$, Beatrice Uziely ${ }^{1}$ and Tamar Peretz ${ }^{1}$ \\ ${ }^{1}$ Department of Oncology, Hadassah and Hebrew University Medical Centre, P.O. Box 12000, Jerusalem 91120, Israel; ${ }^{2}$ Institute of \\ Oncology, Sheba Medical Center, Tel Hashomer, Israel; ${ }^{3}$ Department of Pathology, Hadassah and Hebrew University Medical \\ Centre, Jerusalem, Israel and ${ }^{4}$ Thoracic Pathology Unit, Pathology Institute, Sheba Medical Center, Tel Hashomer, Israel
}

\begin{abstract}
Background: Progastrin-releasing peptide (ProGRP) is a potential marker for small-cell lung cancer (SCLC) in serum; however, it may be more stable in plasma. We investigated a new plasma assay (ProGRPp) and its usefulness in diagnosing and monitoring SCLC.
\end{abstract}

Methods: The marker concentrations were determined on the ARCHITECT i system.

Results: The assay could distinguish SCLC from non-small-cell lung cancer (NSCLC: area under the curve $0.931,95 \% \mathrm{Cl} 0.893-$ 0.969; cross-validated accuracy 0.813 ; sensitivity $84.0 \%$, specificity $96.3 \%$; at $140 \mathrm{pg} \mathrm{ml}^{-1}$ cutoff). The probability of SCLC when ProGRPp was $>140 \mathrm{pg} \mathrm{ml}^{-1}$ was $91.8 \%$, after adjusting for age, gender, and renal dysfunction. The NSCLC patients with ProGRPp $>140 \mathrm{pg} \mathrm{ml}^{-1}$ were at high risk (odds ratio $=37.0, P<0.001$ ) for tumours with neuroendocrine features. False negatives in SCLC were associated with a lack of thyroid transcription factor-1 $(P<0.001)$. A decrease of ProGRPp to $<140 \mathrm{pg} \mathrm{ml}^{-1}$ during chemotherapy was significantly associated with the image-based response $(P<0.001)$, and independently affected progressionfree survival (PFS, relative risk $=2.51, P=0.04$ ) and overall survival $(O S$, relative risk $=4.38, P=0.003)$, after adjustment for imaging response, performance status, and stage.

Conclusions: The ProGRPp assay is specific and sensitive for diagnosing SCLC. Changes in ProGRPp during chemotherapy are significantly associated with image-based response, PFS, and OS.

Small-cell lung cancer (SCLC) accounts for $13 \%$ of all new lung cancer cases annually in the United States (Govindan et al, 2006). Biologically, it is characterised by neuroendocrine (NE) tissue differentiation and the production of various hormones and neuropeptides (Nicholson et al, 2002). One of these specific NE cellular products is the gastrin-releasing peptide (GRP) that is detected in the circulation (Giladi et al, 1993). The extreme instability of this peptide precludes its use as a circulating tumour marker. To solve this problem, an assay was developed to measure the stable gastrin-releasing peptide precursor, progastrin-releasing peptide (ProGRP) (Miyake et al, 1994), considered the most effective circulating diagnostic marker for SCLC (Stieber et al, 1999; Molina et al, 2004; Nisman et al, 2009). A published metaanalysis indicated that a manually performed serum assay for ProGRP has a sensitivity and specificity of 0.716 and 0.921 , respectively, for diagnosing SCLC (Yang et al, 2011).

Recently, Abbott Diagnostics developed a fully automated ARCHITECT chemiluminescent microparticle ProGRP immunoassay. In serum, this assay was comparable with the manual assay, with a sensitivity of $73 \%$ for the detection of SCLC

\footnotetext{
*Correspondence: Dr B Nisman; E-mail: nisman@hadassah.org.il

${ }^{5}$ These authors contributed equally to this work.
}

Received 5 September 2015; revised 16 December 2015; accepted 22 December 2015; published online 26 January 2016

(c) 2016 Cancer Research UK. All rights reserved 0007-0920/16 
(Korse et al, 2012). However, Kim et al (2011) found that ProGRP is more stable in plasma vs serum. There was only a moderate correlation observed between the concentration of ProGRP in serum and plasma when measured by the ARCHITECT assay. The study results suggested that the plasma ProGRP (ProGRPp) assay performs better using plasma. Initial results of a small population study supported the validity of this assertion (Kim et al, 2011). In this study, with patients recruited from two hospitals, we assessed the ability of the ProGRPp assay to discriminate SCLC from nonsmall-cell lung cancer (NSCLC) and its utility in monitoring chemotherapy.

\section{MATERIALS AND METHODS}

Patients. Patients with benign lung diseases (BLD), NSCLC, and SCLC were continuously enrolled at the Oncology Department of Hadassah and Hebrew University Medical Centre in Jerusalem (317 patients) and the Institute of Oncology of Sheba Medical Center in Tel Hashomer (122 patients), between 1 November 2009 and 30 August 2014. Patients included in this study had no previous primary malignant tumour and no antineoplastic therapy after their current cancer diagnosis. The reference ranges for normal ProGRPp concentrations were defined in 100 healthy individuals.

Diagnoses of all lung tumours were histologically confirmed. Patients with NSCLC and SCLC were staged according to TNM classification (Mountain, 1997) and the Veterans Administration Lung Cancer Group staging system (Stahel et al, 1989), respectively. After receiving informed consent from all patients, plasma samples were obtained and stored at $-80^{\circ} \mathrm{C}$ until analysis was performed in the central laboratory of the Hadassah and Hebrew University Medical Center. The diagnosis of large-cell NE carcinoma (LCNEC) required positive staining for at least one of the following NE markers: chromogranin A, synaptophysin, or CD56 (neural cell adhesion molecule), as well as NE morphology (organoid nests with rosette-like and palisading patterns), high mitotic rate, and necrosis. Conventional NSCLC with positive NE markers was referred to NSCLC with NE differentiation (NSCLC-NED) (Travis, 2010). This study was approved by the Institutional Ethical Review Board (0331-09-HMO).

Marker evaluation. The ARCHITECT i system, kindly supplied by Abbott Diagnostics (Wiesbaden, Germany), was used to measure ProGRP in EDTA-treated plasma. The analytical sensitivity or limit of detection (LOD) was $0.5 \mathrm{pg} \mathrm{ml}^{-1}$. The functional sensitivity or limit of quantification (LOQ) is defined as the concentration at which the coefficient of variation exceeds $20 \%$. The LOQ derived from regression analysis of the precision profile was $<3 \mathrm{pg} \mathrm{ml}^{-1}$. The within-assay and between-assay coefficients of variation across the range of 50 to $5000 \mathrm{pg} \mathrm{ml}^{-1}$ of ProGRP were $3-5 \%$. The upper limit of normal (ULN) corresponded to the 95th percentile in healthy individuals, according to the guidelines of the Clinical and Laboratory Standards Institute (Horowitz et al, 2008). Creatinine was measured in all patients and used to calculate the estimated glomerular filtration rate (eGFR) according to the Chronic Kidney Disease (CKD) Epidemiology Collaboration (CKD-EPI) equation (Levey et al, 2009). Staging of CKD was done according to the Kidney Disease Outcomes Quality Initiative (KDOQI) Guidelines (National Kidney Foundation, 2002), with a cutoff of $<60 \mathrm{ml} \mathrm{min}^{-1}$ per $1.73 \mathrm{~m}^{2}$ ( $\geqslant$ stage 3 ).

Monitoring chemotherapy. A total of 52 patients with SCLC were monitored by ProGRPp during chemotherapy. The chemotherapy schedule consisted of 4-6 cycles. Most patients received a combination of platinum with etoposide $(n=50)$ and two patients with irinotecan or gemcitabine. The treatment of patients with limited disease (LD) involved chemotherapy and concurrent thoracic irradiation. Prophylactic cranial irradiation (PCI) was offered to patients with limited or extensive disease (ED) who achieved a complete or partial response to initial therapy. Monitoring of response was performed by imaging techniques. The lesion size measurements were interpreted using the Response Evaluation Criteria in Solid Tumours (RECIST) to define categories of response. Response evaluation was performed after completion of chemotherapy. The marker measurements were performed before each cycle of chemotherapy and 1 month after the last cycle.

Statistical analysis. Four groups of subjects were analysed, healthy individuals and patients with BLD, NSCLC, and SCLC. For numeric variables, the Kruskal-Wallis and Mann-Whitney tests were performed to estimate homogeneity. For categorical variables, Fisher's exact test was applied. Logistic regression was used for prediction. Sensitivity and specificity values were obtained with receiver operating characteristic (ROC) curves. An optimal cutoff value was defined as the maximal Youden's index (Armitage, 1971). Three-fold cross-validation was used to estimate the accuracy of the analysis.

Patients were divided into two categories, based on their response to treatment: responders who attained complete response (CR) or partial response (PR) and nonresponders, including patients with stable disease (SD) or progression (PD). Progressionfree survival (PFS) was defined as the time elapsed between the treatment onset until tumour progression or death from any cause with censoring of patients before a new anticancer treatment or who are lost to follow-up.

Overall survival (OS) was measured from the treatment onset to the last follow-up evaluation or death. A survival analysis was performed by the Kaplan-Meier method and the log-rank test. Cox regression analysis was used to assess the impact of multiple covariates (Cox, 1972). Statistical calculations were performed using SPSS for Windows, Version 10 (SPSS Inc., Chicago, IL, USA). A value of $P<0.05$ was considered statistically significant.

\section{RESULTS}

ProGRPp in healthy individuals and patients with BLD. Analysis of the 100 plasma samples from healthy individuals did not reveal a difference in medians of ProGRPp between males and females (39 vs $40 \mathrm{pg} \mathrm{ml}^{-1}, P=0.42$ ) or a correlation with age $(r=0.06)$. The 95 th percentile of the value (ULN) measured in this group was $64 \mathrm{pg} \mathrm{ml}^{-1}$ (Figure 1). There was no difference between ProGRPp levels in patients with BLD compared with healthy individuals (median: 39 vs 38, $P=0.46$ ). In the BLD group, the marker level was not affected by gender or smoking habits (Table 1). Although the ProGRPp level increased with age, the difference between the two age groups did not reach statistical significance $(P=0.072)$.

The distribution of ProGRPp in patients with various BLDs was analysed (Table 1), including infectious lung disease (ILD), diffuse noninfectious lung diseases (DNILD), obstructive lung diseases (OLD), and solitary pulmonary nodules (SPN). The ProGRPp concentration showed significant heterogeneity with medians of $46,43,35$, and $32 \mathrm{pg} \mathrm{ml}^{-1}$ for patients with each of these individual BLDs, respectively $(P=0.001$; all of these values were in the low range). In the entire combined BLD group, the 95th percentile was $64 \mathrm{pg} \mathrm{ml}^{-1}$, and this was the same as in the group of healthy individuals (Figure 1).

Between-site effect in NSCLC and SCLC cohorts. No difference was observed in the distribution of ProGRPp across two cohorts of NSCLC and SCLC patients recruited at the Hadassah Medical Center and Sheba Medical Center (NSCLC, median, IQR: 40, 


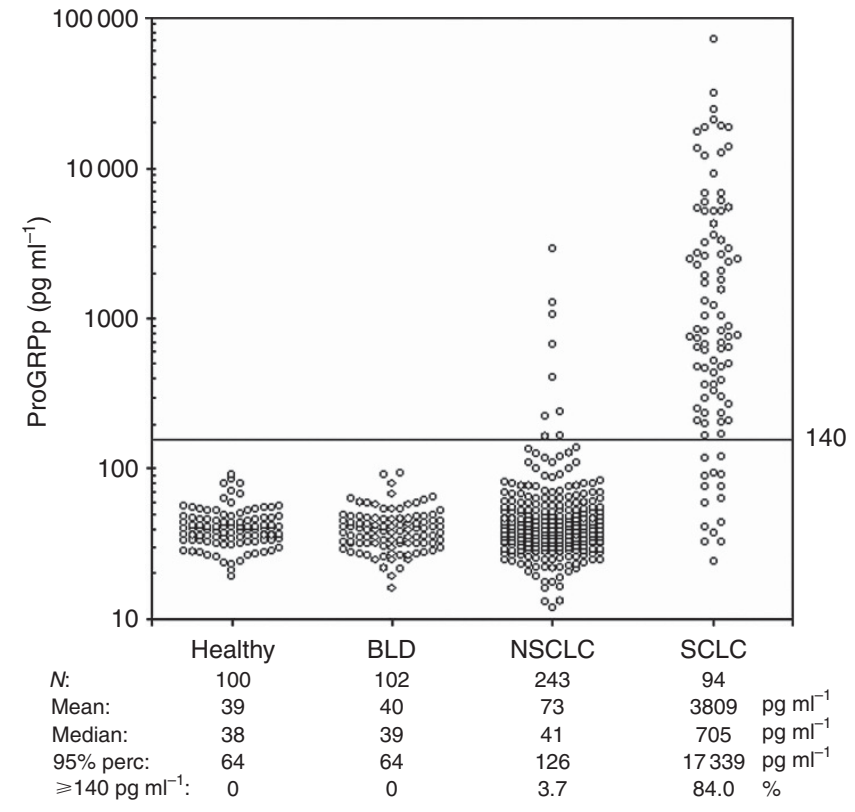

Figure 1. ProGRPp distribution in healthy individuals and patients with BLD, NSCLC, and SCLC. The thin line represents the cutoff value of $140 \mathrm{pg} \mathrm{ml}^{-1}$ with a specificity of $96.3 \%$ and sensitivity of $84 \%$ for distinguishing SCLC from NSCLC. Among 9 NSCLC patients with proGRPp $>140 \mathrm{pg} \mathrm{ml}^{-1}, 4$ patients had pure or combined large-cell neuroendocrine carcinoma $\left(204,405,1268\right.$, and $\left.2861 \mathrm{pg} \mathrm{ml}^{-1}\right)$, 2 patients had NSCLC with neuroendocrine differentiation (678 and $\left.1049 \mathrm{pg} \mathrm{ml}^{-1}\right)$, and 1 patients had stage 4 of chronic kidney disease $\left(166 \mathrm{pg} \mathrm{ml}^{-1}\right) ; 95 \%$ perc $=95 \%$ percentile.

31-55 vs 41, 31-58, $P=0.635$ and SCLC, median, IQR: 790, 2082918 vs $664,243-3176, P=0.991$, respectively).

ProGRPp in patients with NSCLC. The concentration of ProGRPp in patients with NSCLC (median $41 \mathrm{pg} \mathrm{ml}^{-1}$ ) did not differ from that observed in patients with BLD (median 39, $P=0.140$ ) or in healthy individuals (median $38, P=0.474$ ). The 95th percentile of the value measured in the NSCLC group was $126 \mathrm{pg} \mathrm{ml}^{-1}$ ProGRPp (Figure 1). There was a significant positive association of ProGRPp with age $(P=0.009$, Table 1$)$ and a negative correlation with the eGFR $(r=-0.29 P<0.001)$. In 30 patients (12.3\%) with an eGFR $<60 \mathrm{ml} \mathrm{min}^{-1}$ per $1.73 \mathrm{~m}^{2}$ $(\geqslant 3$ stage CKD), the ProGRPp level was significantly higher than in 213 patients with an eGFR $\geqslant 60 \mathrm{ml} \mathrm{min}^{-1}$ per $1.73 \mathrm{~m}^{2}$ (medians: 57 and $38 \mathrm{pg} \mathrm{ml}^{-1}$, respectively, $P<0.001$ ). Among different subtypes of NSCLC, only tumours demonstrating NE features (LCNEC and NSCLC-NED) were characterised by elevated levels of ProGRPp (Table 1).

ProGRPp in patients with SCLC. Significantly higher levels of ProGRPp were found in patients with SCLC compared with healthy individuals, patients with BLD, and those with NSCLC (Figure 1, $P<0.0001$ for all). The ProGRPp assay could differentiate SCLC from BLD, as demonstrated by the large area under the ProGRPp curve $(0.949,95 \%$ CI $0.912-0.987)$ and a higher cross-validated accuracy of 0.865 (Figure 2A). The optimal value for discrimination of SCLC from BLD was $64 \mathrm{pg} \mathrm{ml}^{-1}$, equal to the ULN. In patients with SCLC (Table 1), the ProGRPp concentration was significantly associated with disease stage $(P=0.015)$. A significant heterogeneity by weight loss in ProGRPp levels in three categories $(0,1-10$, and $>10 \mathrm{~kg})$ was found $(P=0.003$, Table 1 and Figure 3$)$.

Among 94 SCLC patients, staining for thyroid transcription factor-1 (TTF1) was analysed in $81(86.2 \%)$ of the patients.

\section{Table 1. ProGRPp in BLD, SCLC, and NSCLC}

\begin{tabular}{|c|c|c|c|}
\hline Characteristics & $n$ & $\begin{array}{c}\text { ProGRPp }\left(\mathrm{pg} \mathrm{ml}^{-1}\right) \\
\text { Median, IQR }\end{array}$ & $P$-value \\
\hline All benign lung diseases & 102 & $39,32-47$ & \\
\hline \multicolumn{4}{|l|}{ Age (years) } \\
\hline $\begin{array}{l}<63 \\
\geqslant 63\end{array}$ & $\begin{array}{l}60 \\
42\end{array}$ & $\begin{array}{l}35,31-43 \\
40,32-52\end{array}$ & 0.072 \\
\hline \multicolumn{4}{|l|}{ Gender } \\
\hline $\begin{array}{l}\text { Male } \\
\text { Female }\end{array}$ & $\begin{array}{l}60 \\
42\end{array}$ & $\begin{array}{l}39,33-49 \\
38,31-45\end{array}$ & 0.322 \\
\hline \multicolumn{4}{|l|}{ Smoking habits } \\
\hline $\begin{array}{l}\text { Nonsmoker } \\
\text { Smoker/Ex }\end{array}$ & $\begin{array}{l}52 \\
50\end{array}$ & $\begin{array}{l}34,29-43 \\
41,34-49\end{array}$ & 0.14 \\
\hline \multicolumn{4}{|l|}{ BLD } \\
\hline $\begin{array}{l}\text { ILD } \\
\text { DNILD } \\
\text { OLD } \\
\text { SPN } \\
\text { All small-cell lung carcinoma }\end{array}$ & $\begin{array}{l}13 \\
35 \\
25 \\
29 \\
94\end{array}$ & $\begin{array}{c}46,40-59 \\
43,37-52 \\
35,32-43 \\
32,29-38 \\
705,220-3319\end{array}$ & $<0.001$ \\
\hline \multicolumn{4}{|l|}{ Age (years) } \\
\hline $\begin{array}{l}\leqslant 63 \\
>63\end{array}$ & $\begin{array}{l}48 \\
46\end{array}$ & $\begin{array}{c}597,211-3746 \\
1439,246-3527\end{array}$ & 0.314 \\
\hline \multicolumn{4}{|l|}{ Gender } \\
\hline $\begin{array}{l}\text { Female } \\
\text { Male }\end{array}$ & $\begin{array}{l}30 \\
64\end{array}$ & $\begin{array}{l}551,204-2273 \\
850,223-4574\end{array}$ & 0.17 \\
\hline \multicolumn{4}{|l|}{ SCLC subtypes } \\
\hline $\begin{array}{l}\text { Combined } \\
\text { Pure }\end{array}$ & $\begin{array}{l}10 \\
84\end{array}$ & $\begin{array}{c}713,32-2225 \\
704,228-4351\end{array}$ & 0.418 \\
\hline \multicolumn{4}{|l|}{ Stage } \\
\hline $\begin{array}{l}\text { Limited } \\
\text { Extensive }\end{array}$ & $\begin{array}{l}35 \\
59\end{array}$ & $\begin{array}{c}568,99-2053 \\
909,323-5271\end{array}$ & 0.015 \\
\hline \multicolumn{4}{|l|}{ Weight loss (kg) } \\
\hline $\begin{array}{l}0 \\
1-10 \\
>10\end{array}$ & $\begin{array}{l}51 \\
33 \\
10\end{array}$ & $\begin{array}{c}540,179-1719 \\
1860,306-4938 \\
7716,766-23124\end{array}$ & 0.003 \\
\hline
\end{tabular}

\section{Performance status}

\begin{tabular}{|l|r|c|c}
$0-1$ & 67 & $790,211-4553$ & \\
$\geqslant 2$ & 27 & $540,291-2349$ & 0.716 \\
All non-small-cell lung carcinoma & 243 & $41,31-56$ &
\end{tabular}

\begin{tabular}{|c|c|c|c|}
\hline \multicolumn{4}{|l|}{ Age } \\
\hline$\leqslant 63$ & 117 & $37,28-51$ & \\
\hline$>63$ & 126 & $44,33-62$ & 0.009 \\
\hline \multicolumn{4}{|l|}{ Gender } \\
\hline Female & 80 & $43,31-57$ & \\
\hline Male & 163 & $39,30-56$ & 0.43 \\
\hline \multicolumn{4}{|c|}{ Smoking habits } \\
\hline Nonsmoker & 55 & $38,29-57$ & \\
\hline Smoker/Ex & 188 & $42,32-56$ & 0.741 \\
\hline \multicolumn{4}{|c|}{ Histological type } \\
\hline Adenocarcinoma & 157 & $41,29-53$ & \\
\hline Squamous & 52 & $41,30-54$ & \\
\hline Large cell & 13 & $58,35-269$ & \\
\hline Other & 21 & $38,26-47$ & 0.087 \\
\hline \multicolumn{4}{|c|}{ Neuroendocrine features (LCNEC or NSCLC-NED) } \\
\hline No & 225 & $39,30-55$ & \\
\hline Yes & 18 & $50,41-678$ & 0.01 \\
\hline \multicolumn{4}{|l|}{ TNM stage } \\
\hline$|-| \mid$ & 26 & $48,32-63$ & \\
\hline III & 84 & $45,33-59$ & \\
\hline IV & 133 & $39,30-52$ & 0.639 \\
\hline \multicolumn{4}{|c|}{ Weight loss $(\mathrm{kg})$} \\
\hline 0 & 159 & $39,30-54$ & \\
\hline $1-10$ & 61 & $36,30-51$ & \\
\hline$>10$ & 23 & $30,37-49$ & 0.53 \\
\hline \multicolumn{4}{|c|}{ Performance status } \\
\hline $0-1$ & 191 & $40,30-53$ & \\
\hline$\geqslant 2$ & 52 & $44,32-63$ & 0.197 \\
\hline
\end{tabular}

Abbreviations: $B L D=$ benign lung disease; $D N I L D=$ diffuse noninfectious lung disease; $I L D=$ infectious lung disease; $I Q R=$ interquartile range; $L C N E C=$ large-cell neuroendocrine carcinoma; $\mathrm{NSCLC}=$ non-small-cell lung carcinoma; NSCLC-NED = NSCLC with neuroendocrine differentiation; $\mathrm{OLD}=$ obstructive lung disease; ProGRPp = plasma progastrin-releasing peptide; $\mathrm{SCLC}=$ small-cell lung carcinoma; SPN = solitary pulmonary nodule; TNM = tumour, node, and metastasis. 

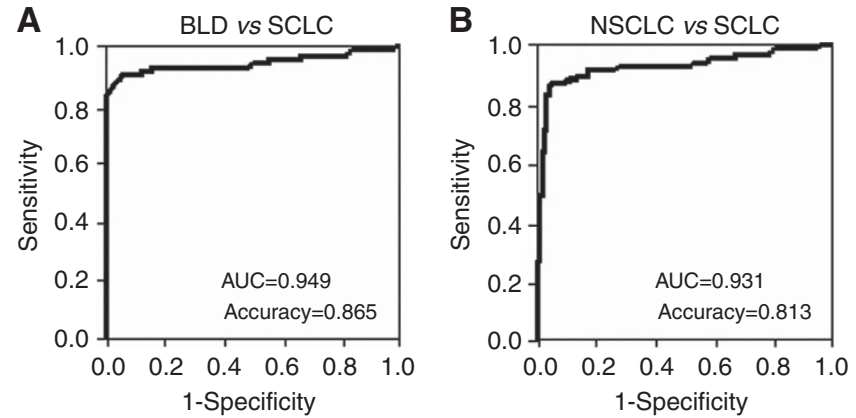

Figure 2. Receiver operating characteristic curves for discrimination of SCLC from BLD (A) and NSCLC (B). Large values of ProGRPp predicted SCLC. The cross-validated accuracy is 0.865 in the model of SCLC vs $\operatorname{BLD}(\mathbf{A})$ and 0.813 in the model SCLC vs NSCLC (B). AUC = area under the ProGRPp curve.

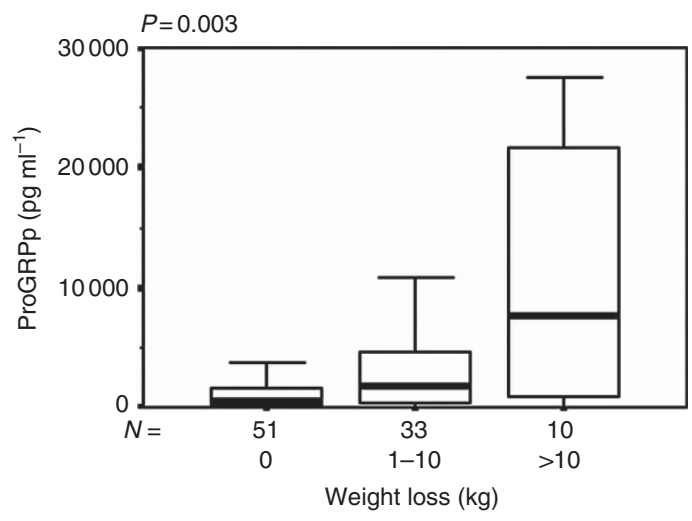

Figure 3. Plasma progastrin-releasing peptide (ProGRPp) by the weight loss in 94 patients with SCLC. Each box plot shows the median (heavy line), quartiles (box ends), and extreme values (whiskers) within the category shown. $P$ value is derived from Kruskal-Wallis test.

Tumours from 68 of these patients (84\%) were positive and from 13 patients (16\%) were negative. Significantly high levels of ProGRPp were found in patients with TTF1-positive tumours compared with those with TTF1-negative tumours (medians, 1124 and $81 \mathrm{pg} \mathrm{ml}^{-1}$, respectively, $P<0.001$ ).

Analysis of the ROC curve. In 337 patients, the area under the ROC for ProGRPp was 0.931 (95\% CI 0.893-0.969) and the crossvalidated accuracy was 0.813 in differentiating SCLC from NSCLC (Figure 2B). The Youden's index defined an optimal cutoff of $140 \mathrm{pg} \mathrm{ml}^{-1}$. The sensitivity and specificity were $84 \%$ and $96.3 \%$, respectively (with positive and negative predictive values of $89.8 \%$ and 94\%, respectively). At this cutoff, the sensitivities of the ProGRPp assay in patients with limited and extensive disease were $70.6 \%$ and $91.7 \%(P=0.012)$, respectively. Based on the logistic regression, the probability of SCLC when ProGRPp was $>140 \mathrm{pg} \mathrm{ml}^{-1}$ was $91.8 \%$, after adjusting for age, gender, and eGFR.

Ten patients had SCLC combined with NSCLC. The sensitivity in this group was $70 \%$, and this was not significantly different from that in pure SCLC $(P=0.19)$. The rates of elevated levels of ProGRPp in patients with NSCLC classified as LCNEC and NSCLC-NED were $36.4 \%$ (4 of 11) and $28.6 \%$ (2 of 7), respectively. Logistic regression analysis showed that NSCLC patients presenting with ProGRPp $>140 \mathrm{pg} \mathrm{ml}^{-1}$ were at a high risk (odds ratio $(\mathrm{OR})=37.0,95 \%$ CI 8.2-166.3, $P<0.001)$ for tumours with $\mathrm{NE}$ features (LCNEC and NSCLC-NED). In SCLC, negative staining
Table 2. Changes of proGRPp levels during chemotherapy in SCLC patients

\begin{tabular}{|c|c|c|c|}
\hline Chemotherapy & $\begin{array}{c}\text { Responders } \\
\text { CR }+ \text { PR } \\
n=32\end{array}$ & $\begin{array}{c}\text { Nonresponders } \\
\text { SD + PD } \\
n=20\end{array}$ & $P$-value \\
\hline Pretreatment, median & 790 & 2821 & \\
\hline IQR $\left(\mathrm{pg} \mathrm{ml}^{-1}\right),>140 \mathrm{pg} \mathrm{ml}^{-1}(\%)$ & $291-3176,90.6$ & $820-7791,100$ & 0.102 \\
\hline Second course, median & 215 & 1424 & \\
\hline IQR $\left(\mathrm{pg} \mathrm{ml}^{-1}\right),>140 \mathrm{pg} \mathrm{ml}^{-1}(\%)$ & $51-675,56.3$ & $272-3796,90$ & 0.006 \\
\hline Third course, median & 51 & 1849 & \\
\hline IQR $\left(\mathrm{pg} \mathrm{ml}^{-1}\right),>140 \mathrm{pg} \mathrm{ml}^{-1}(\%)$ & $41-201,37.5$ & $452-5752,100$ & $<0.001$ \\
\hline Fourth course, median & 50 & 2167 & \\
\hline IQR $\left(\mathrm{pg} \mathrm{ml}^{-1}\right),>140 \mathrm{pg} \mathrm{ml}^{-1}(\%)$ & $38-183,34.4$ & $492-5942,100$ & $<0.001$ \\
\hline Fifth course, median & 51 & 2429 & \\
\hline IQR $\left(\mathrm{pg} \mathrm{ml}^{-1}\right),>140 \mathrm{pg} \mathrm{ml}^{-1}(\%)$ & $38-99,12.5$ & $443-9536,100$ & $<0.001$ \\
\hline After treatment, median & 47 & 3171 & \\
\hline IQR $\left(\mathrm{pg} \mathrm{ml}^{-1}\right),>140 \mathrm{pg} \mathrm{ml}^{-1}(\%)$ & $35-128,12.5$ & $335-6250,100$ & 0.001 \\
\hline Median $\mathrm{OS}^{\mathrm{a}}$, months & 14.6 & 9.5 & \\
\hline $95 \%$ confidence interval & $11.6-17.6$ & $4.9-14.1$ & 0.004 \\
\hline Median PFS ${ }^{a}$, months & 6.7 & 3.8 & \\
\hline $95 \%$ Confidence interval & $5.9-7.5$ & $2.8-4.9$ & $<0.001$ \\
\hline \multicolumn{4}{|c|}{ 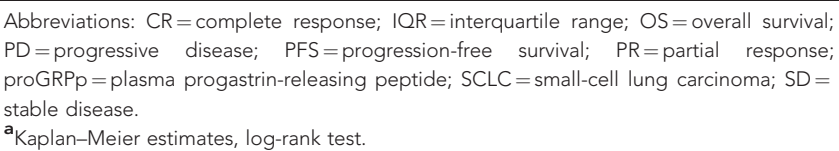 } \\
\hline
\end{tabular}

for TTF1 was predictive of low levels of ProGRPp $\left(\leqslant 140 \mathrm{pg} \mathrm{ml}^{-1}\right.$; $\mathrm{OR}=12.1,95 \%$ CI 3.1-47.7, $P<0.001$ ).

The measurements of ProGRPp were performed in the subset of NSCLC patients with epidermal growth factor receptor (EGFR) mutations $(n=18)$ who progressed on the EGFR tyrosine kinase inhibitor (TKI) therapy. Before treatment, the mean, median, and IQR concentration of ProGRP were 50, 34-68 $\mathrm{pg} \mathrm{ml}^{-1}$, respectively. Of the 18 patients at the time of progression, 2 demonstrated elevated ProGRPp levels: 151 and $388 \mathrm{pg} \mathrm{ml}^{-1}$. Transformation of NSCLC into SCLC was confirmed in these patients with repeated biopsies.

Monitoring chemotherapy in SCLC by ProGRPp. According to imaging evaluations from 52 patients participating in a monitoring study, 8 and 24 patients achieved CR and PR, respectively. In all, 13 patients had SD and the remaining 7 patients progressed during treatment. The patients were assigned to two groups: responders $(\mathrm{CR}+\mathrm{PR})$ and nonresponders $(\mathrm{SD}+\mathrm{PD})$. Imaging response to therapy in these two groups was strongly associated with OS and PFS (Table 2). Patients with LD $(n=14)$ better responded to chemotherapy than those with $\mathrm{ED}(n=38)(92.9 \%$ vs $47.4 \%$, $P=0.004)$. The pretreatment concentration of ProGRPp was not significantly different in responders compared with nonresponders $(P=0.102)$. However, during all chemotherapy, ProGRPp levels were significantly lower in responders compared with nonresponders (Table 2). Only in responders, ProGRPp showed a strong decrease from cycle 1 to $2\left(790\right.$ vs $215 \mathrm{pg} \mathrm{ml}^{-1}$, $P=0.0004)$ and from cycle 2 to $3\left(215\right.$ vs $51 \mathrm{pg} \mathrm{ml}^{-1}$, $P=0.0003$ ). In nonresponders, the initial decrease (from cycle 1 to 2) was not substantial $(P=0.177)$ and was followed by an increase (Table 2).

We used ROC curve analysis to explore ProGRPp levels measured at imaging after chemotherapy to estimate the optimal sensitivity/specificity cutoff for discrimination of responders from nonresponders. The area under the ProGRPp curve was 0.940 (95\% CI $0.868-1.012$ ). The $\leqslant 140 \mathrm{pg} \mathrm{ml}^{-1}$ cutoff for ProGRPp levels, defined by the Youden's index, demonstrated an accuracy of 0.776 in discriminating responders from nonresponders. The rates 

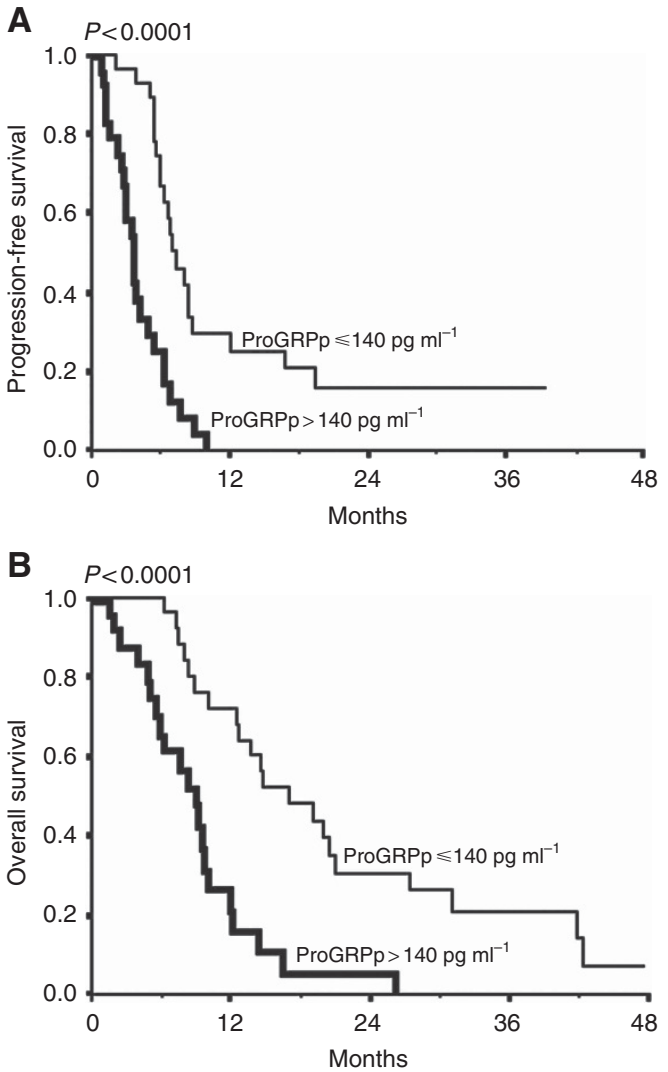

Figure 4. Kaplan-Meier estimates in SCLC with respect to the level of proGRPp at the completion of chemotherapy. (A) Progression-free survival. (B) Overall survival.

of elevated levels in responders and nonresponders were $90.6 \%$ and $100 \%$ before treatment and $12.5 \%$ and $100 \%$ after treatment, respectively (Table 2 ).

Among 14 patients with limited disease and 38 patients with extensive disease, a decline of ProGRPp below the cutoff after chemotherapy was observed in $12(85.7 \%)$ and $16(42.1 \%)$ patients, respectively $(P=0.011)$. The decline of ProGRPp after chemotherapy $<140 \mathrm{pg} \mathrm{ml}^{-1}$ was strongly associated with the objective image-based response (Fisher's exact test $P<0.0001$ ). After adjustment for stage and the Eastern Cooperative Oncology Group (ECOG) performance status (PS), the decline of ProGRPp retained statistical significance $(\mathrm{OR}=44.4,95 \%$ CI $4.8-409.8, P=0.001)$.

The PCI was administered to 13 of 28 (46\%) SCLC patients who achieved a ProGRPp response and to none of the 24 patients who had marker level $>140 \mathrm{pg} \mathrm{ml}^{-1}$ after chemotherapy.

The median PFS and OS (Figure 4A and B) for patients with low ProGRPp levels $\left(\leqslant 140 \mathrm{pg} \mathrm{ml}^{-1}\right)$ were longer than for those with elevated ( $>140 \mathrm{pg} \mathrm{ml}^{-1}$ ) levels (6.9 vs 3.8 months, $P<0.001$ and 16.9 vs 9.0 months, $P<0.0001$, respectively). In multivariate analysis, the decline of ProGRPp below the cutoff after chemotherapy independently affected PFS and OS (Table 3) after adjustment for ECOG PS, stage, and imaging tumour response.

Patients responding to chemotherapy by imaging evaluations, with levels of ProGRPp below the cutoff, demonstrated significantly longer median PFS (7.4 vs 5.1 months, $P=0.022$ ) and OS (16.9 vs 9.2 months, $P=0.025$ ) compared with those with ProGRPp levels that remained elevated. In addition, the decline of ProGRPp after chemotherapy below $64 \mathrm{pg} \mathrm{ml}^{-1}$ (ULN) retained a significant association with complete image-based response $(\mathrm{OR}=12.3$, 95\% CI 1.3-115.7, $P=0.030)$, after adjustment for stage and ECOG PS.
Table 3. Multivariate Cox's regression: relative risk in patients with SCLC $(n=52)$

\begin{tabular}{|c|c|c|c|}
\hline Characteristics & $\begin{array}{c}\text { Relative } \\
\text { risk }\end{array}$ & $95 \% \mathrm{Cl}$ & $P$-value \\
\hline \multicolumn{4}{|l|}{ Progression-free survival } \\
\hline Performance status $(0-1$ vs $\geqslant 2)$ & 2.48 & $1.13-5.46$ & 0.024 \\
\hline Stage (limited vs extensive) & 1.37 & $0.60-3.17$ & 0.456 \\
\hline Response $(\mathrm{CR}+\mathrm{PR}$ vs SD + PD) & 1.07 & $0.44-2.60$ & 0.88 \\
\hline ProGRPp ( $\leqslant 140$ vs $>140 \mathrm{pg} \mathrm{ml}^{-1}$ ) & 2.51 & $1.05-6.00$ & 0.039 \\
\hline \multicolumn{4}{|l|}{ Overall survival } \\
\hline Performance status $(0-1$ vs $\geqslant 2)$ & 2.57 & $1.15-5.74$ & 0.022 \\
\hline Stage (limited vs extensive) & 1.27 & $0.55-2.95$ & 0.583 \\
\hline Response (CR + PR vs SD + PD) & 1.35 & $0.56-3.36$ & 0.513 \\
\hline ProGRPp ( $\leqslant 140$ vs $\left.>140 \mathrm{pg} \mathrm{ml}^{-1}\right)$ & 4.38 & $1.68-11.5$ & 0.003 \\
\hline
\end{tabular}

Abbreviations: $\mathrm{CR}=$ complete response; $\mathrm{PD}=$ progressive disease; $\mathrm{PR}=$ partial response; ProGRPp = plasma progastrin-releasing peptide; $\mathrm{SCLC}=$ small-cell lung carcinoma; $\mathrm{SD}=$ stable disease.

\section{DISCUSSION}

The measurement of ProGRP, by manual assay in serum, was demonstrated over the past decade to be a promising diagnostic marker in patients with SCLC. However, when ProGRP was measured by ARCHITECT, there was better stability of the analyte in plasma than in serum; apparently, the analyte is affected by the serine protease thrombin during the clotting process (Nordlund et al, 2008). Data suggested that a change from using serum to plasma could improve the diagnostic performance of the assay. To investigate, we measured ProGRPp in four groups: healthy individuals and patients with BLD, SCLC, and NSCLC.

In our study, the ULN of ProGRPp levels measured in apparently healthy individuals $\left(64 \mathrm{pg} \mathrm{ml}^{-1}\right)$ was approximately the same as the value presented in the manufacturer's (Abbott ARCHITECT ProGRP package insert, 2009) instructions $\left(65 \mathrm{pg} \mathrm{ml}^{-1}\right)$ and somewhat higher than that reported in a recent study exploring the EDTA plasma matrix (Korse et al, 2015) of the new Elecsys (Roche Diagnostics GmbH, Penzberg, Germany) ProGRP assay $\left(60 \mathrm{pg} \mathrm{ml}^{-1}\right)$. Gender and age had no impact on ProGRPp concentrations in this group. We found significant heterogeneity of the marker distribution in the group of patients with BLD, with increased levels observed in patients with infectious and diffuse lung diseases. Previously, patients with sarcoidosis and idiopathic pulmonary fibrosis had elevated levels of ProGRP in their serum as compared with healthy individuals (Shijubo et al, 1996). The authors suggested that GRP may play a role during the processes of inflammation and remodelling in interstitial lung diseases.

A weak positive correlation was observed between ProGRPp and age, both in patients with BLD and NSCLC. This may be because of an association between ageing and some benign lung conditions, such as sarcoidosis and idiopathic pulmonary fibrosis. The pre-existence of these conditions in many patients with NSCLC may explain the ProGRPp age dependence. Despite the significant heterogeneity in the distribution of ProGRPp seen across groups of patients with various BLD, the 95th percentile of ProGRPp values measured in the group as a whole was not different from the ULN $\left(64 \mathrm{pg} \mathrm{ml}^{-1}\right)$. The calculated 95th percentile concentrations of ProGRPp $\left(126 \mathrm{pg} \mathrm{ml}^{-1}\right)$ in NSCLC patients from our study, measured with the ARCHITECT, was higher than reported with the Elecsys (Roche Diagnostics $\mathrm{GmbH}$ ) assay $\left(84 \mathrm{pg} \mathrm{ml}^{-1}\right.$ ) (Korse et al, 2015).

In the SCLC group there was a significant positive association of weight loss with ProGRPp concentration. This could be explained by the previously described function of mature GRP as an endogenous satiety factor (Gutzwiller et al, 1994) mediated by the GRP receptor (Hampton et al, 1998; Ladenheim et al, 2002). 
In a randomised, double-blind, placebo-controlled trial on healthy men, intravenous infusions of GRP decreased spontaneous food intake and calorie consumption (Gutzwiller et al, 1994). It should be said that most of the ProGRP was suggested to process to GRP. A high correlation between these two molecules in tissue extracts was observed (Miyake et al, 1994). The finding in the present study of a strong association $(P=0.003)$ of high levels of ProGRPp $\left(>10000 \mathrm{pg} \mathrm{ml}^{-1}\right.$ ) with obvious weight loss $(>10 \mathrm{~kg})$ supports the hypothesis that proGRPp may contribute to the development of cachexia in SCLC patients.

In the ROC model considering SCLC vs NSCLC, ProGRPp yielded an area under curve of 0.931 with a cross-validation accuracy of 0.813 . From this model, the $140 \mathrm{pg} \mathrm{ml}^{-1}$ cutoff gave a specificity of $96.3 \%$ and sensitivity of $84 \%$, and this appears to be better than performance characteristics of the manual serum ProGRP assay, with a reported specificity of $92.1 \%$ and sensitivity of $71.6 \%$ (Yang et al, 2011) from meta-analysis. In addition, the values were comparable with the results from a recent multicenter evaluation of the new Elecsys (Roche Diagnostics $\mathrm{GmbH}$ ) automated serum ProGRP immunoassay (95\% specificity and 78.3\% sensitivity) (Korse et al, 2015).

In our study, $\sim 12 \%$ of NSCLC patients had chronic kidney disease (stage $\geqslant 3$ ). Although the effect of renal insufficiency on ProGRPp in patients with NSCLC was significant, it did not notably reduce the diagnostic performance of the assay. Only one patient with an eGFR of $24 \mathrm{ml} \mathrm{min}^{-1}$ per $1.73 \mathrm{~m}^{2}$ had an elevated ProGRPp $>140 \mathrm{pg} \mathrm{ml}^{-1}$. These data confirm the observations of other authors (Korse et al, 2012), indicating that ProGRP results in patients with an eGFR $<30 \mathrm{ml} \mathrm{min}^{-1}$ per $1.73 \mathrm{~m}^{2}$ should be interpreted with care. After adjusting for age, gender, and eGFR, the probability of SCLC when ProGRP was $>140 \mathrm{pg} \mathrm{ml}^{-1}$ was 91.8\%. If the ProGRPp cutoff used to diagnose SCLC was raised from 140 to $400 \mathrm{pg} \mathrm{ml}^{-1}$, the specificity increased from $96.3 \%$ to $98.4 \%$, with a decrease in the sensitivity from $84 \%$ to $66.9 \%$. This additional cutoff could be used for lowering the confounding effect of renal dysfunction.

Previously, Goto et al (1999), in a study on 544 patients with NSCLC, showed the usefulness of serum ProGRP assay for detecting tumours with a small-cell carcinoma component (combined SCLC) and LCNEC. The present study demonstrated the feasibility of the ProGRPp assay in the diagnosis of combined SCLC/NSCLC, with a high sensitivity of 70\%. Furthermore, 11 and 7 patients among the NSCLC group had tumours classified as LCNEC and NSCLC-NED, respectively. The elevated levels of ProGRPp (>140 $\mathrm{pg} \mathrm{ml}^{-1}$ ) were registered in $36.4 \%$ and $28.9 \%$, respectively, of these patients. Comparable rates of elevated serum ProGRP levels were reported by Kudo et al (2011) in patients with LCNEC (44\%).

Logistic regression analysis confirmed that NSCLC patients presenting with ProGRPp $>140 \mathrm{pg} \mathrm{ml}^{-1}$ are at a higher risk $(\mathrm{OR}=37.0, P<0.001)$ for tumours with NE features. Taking these data into account, the detection of elevated levels of ProGRPp $\left(>140 \mathrm{pg} \mathrm{ml}^{-1}\right)$ in patients with NSCLC may justify further pathological evaluation for the presence of SCLC components or LCNEC. Thus, the simple single laboratory test may be useful as a supplement to histology for the diagnosis. Clinically, the results of the ProGRPp assay could have an impact on the treatment plan by indicating a change to etoposide containing regimens as a better option for combined SCLC and LCNEC (Iyoda et al, 2014).

An important clinical application for this highly specific ProGRPp assay may be early assessment, as it can be performed much more rapidly than biopsy in many cases. In some patients, one can obtain only tiny amounts of tissue that may be inconclusive, whereas rendering a rebiopsy may be nearly impossible in patients with delicate clinical conditions. This might also be of great clinical relevance, for example in patients with superior vena cava syndrome, when deciding whether to begin therapy (following stent insertion) with chemoradiation or with chemotherapy followed by chemoradiation.

Transformation of NSCLC into SCLC is one of the rare mechanisms of acquired resistance to TKIs in NSCLC patients with mutated EGFR (Sequist et al, 2011; Oser et al, 2015). In our study, among 18 patients with EGFR mutations who developed resistance to TKIs, only 2 patients with L858R mutation had elevated ProGRPp. Biopsy revealed histological transformation to SCLC. These data suggest that ProGRPp may be useful for early detection of SCLC transformation in cases resistant to EGFR-TKI therapy.

An interesting finding not previously reported was the correlation between the expression of TTF1 and levels of ProGRPp. In our study, $53.9 \%$ of patients with TTF1-negative tumours and only $8.8 \%$ of patients with TTF1-positive tumours had low levels of ProGRPp ( $\left.<140 \mathrm{pg} \mathrm{ml}^{-1}, P=0.001\right)$. We did not detect increased ProGRPp levels in several samples of small-cell NE tumours originating from sites outside the lung that did not express TTF1. Furthermore, in low-grade lung neuroendocrine tumours, positive staining for TTF1 was found only in cases positive for GRP immunoreactivity (Granberg et al, 2006). It is unclear whether TTF1-negative SCLC has different biological characteristics. From a clinical point of view, however, the absence of TTF1 in $~ 10-20 \%$ of SCLC patients (Travis, 2009; Rekhtman, 2010) should be considered when using the ProGRP assay in patients with this phenotype.

Our study showed a high performance of the ProGRPp assay in differentiating SCLC from BLD (area under the curve 0.949 and cross-validated accuracy of 0.865 ), suggesting its potential in monitoring the response to chemotherapy. In the analysis of imaging response, we combined the two categories CR and PR into one group of responders. This was justified by the common post treatment option (PCI) for these two response categories in limited and extensive disease (Jett et al, 2013). The nonresponder group included patients who progressed during treatment or had stable disease. These two imaging response groups differed significantly regarding the prognosis in terms of PFS and OS. In accordance with previous observations on serum ProGRP (Holdenrieder et al, 2008; Wójcik et al, 2008), we found that the ProGRPp level in responders fell during consecutive courses. Only in responders, ProGRPp showed a strong decrease after the first and second cycles, whereas nonresponders had a small initial decrease followed by an increase. This decrease in responders was also observed by others (Wójcik et al, 2008) and was related to the reduction of cancer cells by the cytotoxic treatment. Throughout all chemotherapy courses, ProGRPp levels were significantly lower in responders compared with nonresponders.

Previous studies reported there was a relationship between the changes in serum ProGRP and the imaging response and prognosis (Yamaguchi et al, 1995; Sunaga et al, 1999; Wójcik et al, 2008; Holdenrieder et al, 2008). In the present study, we constructed the ROC model comparing ProGRPp levels in responders and nonresponders. From this model, the $\leqslant 140 \mathrm{pg} \mathrm{ml}^{-1}$ cutoff was found to discriminate the two response groups (same as the cutoff used in the diagnosis of SCLC). The decline of ProGRPp below this cutoff during chemotherapy was strongly associated with the objective image-based response $(P<0.0001)$.

The patients with ProGRPp levels $<140 \mathrm{pg} \mathrm{ml}^{-1}$ after completion of chemotherapy showed higher median PFS and median OS compared with patients with marker levels above this value. In the Cox's proportional hazard model, the ProGRPp response retained significance as a factor affecting PFS and OS, after adjustment for imaging response, ECOG PS, and stage. These data suggest that the ProGRPp response contributes additional independent information to the imaging response. Actually, in accordance with the results of a previous study on serum ProGRP (Okusaka et al, 1997), we observed that responding patients with ProGRPp levels below the cutoff had a better prognosis than those with marker levels 
above the cutoff. The strong association of ProGRPp response with prognosis may be an important indication of the markers usefulness in monitoring therapy and the prediction of residual tumour after treatment. The observed relationship between the marker decline after chemotherapy below $64 \mathrm{pg} \mathrm{ml}^{-1}$ (optimal threshold for discrimination of SCLC from BLD) and complete imaging response supports this line of reasoning. It is of interest that in the group of responders, only patients with ProGRPp levels $<140 \mathrm{pg} \mathrm{ml}^{-1}$ were treated after chemotherapy with PCI. Given the current findings, the ProGRPp measurements could be integrated with imaging to guide the selection of patients for PCI. Additional studies are needed to validate this type of approach.

In summary, ProGRPp is a highly specific marker for NE lung tumours, with the highest sensitivity in the most common highgrade NE lung malignancy, namely SCLC (pure and combined), and moderate sensitivity in other NE tumours originating from the lung. The robustness of ProGRPp as a marker for the diagnosis of SCLC was demonstrated by the results of the ROC analysis in the cross-validated model of SCLC $v s$ NSCLC, with a sensitivity of $84 \%$ and specificity of $96.3 \%$, at a cutoff of $140 \mathrm{pg} \mathrm{ml}^{-1}$. Elevation of ProGRPp beyond this cutoff in patients with NSCLC may indicate further pathological examination with regard to combined SCLC or LCNEC. The change in the ProGRPp after chemotherapy showed a significant association with imaging assessments of response, PFS, and OS. Because of its high sensitivity and specificity, plasma ProGRP could be the marker of choice for the diagnosis and chemotherapy monitoring of patients with SCLC.

\section{ACKNOWLEDGEMENTS}

We thank Dr Mario Baras of the Hebrew University, Hadassah School of Public Health, for advice on the statistical analysis.

\section{CONFLICT OF INTEREST}

The authors declare no conflict of interest.

\section{REFERENCES}

Abbott ARCHITECT ProGRP package insert (2009).

Armitage P (1971) Statistical Methods in Medical Research. Blackwell: Oxford, UK.

Cox DR (1972) Regression models and life-tables. J R Stat Soc 34: 187-202.

Giladi E, Nagalla SR, Spindel ER (1993) Molecular cloning and characterization of receptors for the mammalian bombesin-like peptides. J Mol Neurosci 4: 41-54.

Goto K, Kodama T, Hojo F, Kubota K, Kakinuma R, Matsumoto T, Ohmatsu H, Sekine I, Nagai K, Nishiwaki Y (1999) Clinicopathologic characteristics of patients with nonsmall cell lung carcinoma with elevated serum progastrin-releasing peptide levels. Cancer 15(82): 1056-1061.

Govindan R, Page N, Morgensztern D, Read W, Tierney R, Vlahiotis A, Spitznagel EL, Piccirillo J (2006) Changing epidemiology of small cell lung cancer in the United States over the last 30 years: analysis of the surveillance, epidemiologic, and end results database. J Clin Oncol 24: 4539-4544.

Granberg D, Skogseid B, Welin S, Orlefors H, Oberg K, Wilander E (2006) Gastrin-releasing-peptide in neuroendorine tumours. Acta Oncol 45: 23-27.

Gutzwiller JP, Drewe J, Hildebrand P, Rossi L, Lauper JZ, Beglinger C (1994) Effect of intravenous human gastrin-releasing peptide on food intake in humans. Gastroenterology 106: 1168-1173.

Hampton LL, Ladenheim EE, Akeson M, Way JM, Weber HC, Sutliff VE, Jensen RT, Wine LJ, Arnheiter H, Battey JF (1998) Loss of bombesininduced feeding suppression in gastrin-releasing peptide receptor-deficient mice. Proc Natl Acad Sci USA 95: 3188-3192.
Holdenrieder S, von Pawel J, Dankelmann E, Duell T, Faderl B, Markus A, Siakavara M, Wagner H, Feldmann K, Hoffmann H, Raith H, Nagel D, Stieber P (2008) Nucleosomes, ProGRP, NSE, CYFRA 21-1, and CEA in monitoring first-line chemotherapy of small cell lung cancer. Clin Cancer Res 14: 7813-7821.

Horowitz GL, Altail S, Boyd JC, Ceriotti F, Garg U, Horn P, Pesce A, Sine HE, Zakowski J (2008) Defining, Establishing, and Verifying Reference Intervals in the Clinical Laboratory, 3rd edn. Clinical and Laboratory Standards Institute: Pennsylvania, PA, USA.

Iyoda A, Makino T, Koezuka S, Otsuka H, Hata Y (2014) Treatment options for patients with large cell neuroendocrine carcinoma of the lung. Gen Thorac Cardiovasc Surg 62: 351-356.

Jett JR, Schild SE, Kesler KA, Kalemkerian GP (2013) Treatment of small cell lung cancer: diagnosis and management of lung cancer, 3rd ed. American College of Chest Physicians evidence-based clinical practice guidelines. Chest 143(5 Suppl): e400S-e4419.

Kim HR, Oh IJ, Shin MG, Park JS, Choi HJ, Ban HJ, Kim KS, Kim YC, Shin JH, Ryang DW, Suh SP (2011) Plasma proGRP concentration is sensitive and specific for discriminating small cell lung cancer from nonmalignant conditions or non-small cell lung cancer. J Korean Med Sci 26: 625-630.

Korse CM, Taal BG, Vincent A, van Velthuysen ML, Baas P, Buning-Kager JC, Linders TC, Bonfrer JM (2012) Choice of tumour markers in patients with is dependent on the histological grade. A marker study of Chromogranin A Neuron specific enolase, Progastrin-releasing peptide and cytokeratin fragments. Eur J Cancer 48: 2662-2671.

Korse CM, Holdenrieder S, Zhi XY, Zhang X, Qiu L, Geistanger A, Lisy MR, Wehnl B, van den Broek D, Escudero JM, Standop J, Hu M, Molina R (2015) Multicenter evaluation of a new progastrin-releasing peptide (ProGRP) immunoassay across Europe and China. Clin Chim Acta 438: 388-395.

Kudo K, Ohyanagi F, Horiike A, Miyauchi E, Yanagitani N, Hoshi R, Satoh Y, Motoi N, Hamanaka W, Ishikawa Y, Mun M, Sakao Y, Okumura S, Nakagawa K, Horai T, Nishio M (2011) Clinicopathological findings of non-small-cell lung cancer with high serum progastrin-releasing peptide concentrations. Lung Cancer 74: 401-404.

Ladenheim EE, Hampton1 LL, Whitney AC, White WO, Battey JF, Moran TH (2002) Disruptions in feeding and body weight control in gastrin-releasing peptide receptor deficient mice. J Endocrinol 174: 273-281.

Levey AS, Stevens LA, Schmid CH, Zhang YL, Castro 3rd AF, Feldman HI, Kusek JW, Eggers P, Van Lente F, Greene T, Coresh J (2009) CKD-EPI (Chronic Kidney Disease Epidemiology Collaboration). A new equation to estimate glomerular filtration rate. Ann Intern Med 150: 604-612.

Miyake Y, Kodama T, Yamaguchi K (1994) Pro-gastrin-releasing peptide (31-98) is a specific tumour marker in patients with small cell lung carcinoma. Cancer Res 54: 2136-2140.

Molina R, Auge JM, Alicarte J, Filella X, Viñolas N, Ballesta AM (2004) Pro-gastrin-releasing peptide in patients with benign and malignant diseases. Tumour Biol 25: 56-61.

Mountain CF (1997) Revisions in the international system for staging lung cancer. Chest 111: 1710-1717.

National Kidney Foundation (2002) KDOQI Clinical Practice Guidelines for Chronic Kidney Disease: evaluation, classification and stratification. Am J Kidney Dis 39(Suppl 1): 1-222.

Nicholson SA, Beasley MB, Brambilla E, Hasleton PS, Colby TV, Sheppard MN, Falk R, Travis WD (2002) Small cell lung carcinoma (SCLC): a clinicopathologic study of 100 cases with surgical specimens. Am J Surg Pathol 26: 1184-1197.

Nisman B, Biran H, Ramu N, Heching N, Barak V, Peretz T (2009) The diagnostic and prognostic value of ProGRP in lung cancer. Anticancer Res 29: 4827-4832.

Nordlund MS, Bjerner J, Warren DJ, Nustad K, Paus E (2008) Progastrinreleasing peptide: stability in plasma/serum and upper reference limit. Tumour Biol 29: 204-210.

Okusaka T, Eguchi K, Kasai T, Kurata T, Yamamoto N, Ohe Y, Tamura T, Shinkai T, Saijo N (1997) Serum levels of pro-gastrin-releasing peptide for follow-up of patients with small cell lung cancer. Clin Cancer Res 3: 123-127.

Oser MG, Niederst MJ, Sequist LV, Engelman JA (2015) Transformation from non-small-cell lung cancer to small-cell lung cancer: molecular drivers and cells of origin. Lancet Oncol 16: e165-e172.

Rekhtman N (2010) Neuroendocrine tumors of the lung. An update. Arch Pathol Lab Med 134: 1628-1638. 
Sequist LV, Waltman BA, Dias-Santagata D, Digumarthy S, Turke AB, Fidias P, Bergethon K, Shaw AT, Gettinger S, Cosper AK, Akhavanfard S, Heist RS, Temel J, Christensen JG, Wain JC, Lynch TJ, Vernovsky K, Mark EJ, Lanuti M, Iafrate AJ, Mino-Kenudson M, Engelman JA (2011) Genotypic and histological evolution of lung cancers acquiring resistance to EGFR inhibitors. Sci Transl Med 23(3): 75ra26.

Shijubo N, Yamaguchi K, Hirasawa M, Shibuya Y, Inuzuka M, Kodama T, Abe S (1996) Progastrin-releasing peptide(31-98) in idiopathic pulmonary fibrosis and sarcoidosis. Am J Respir Crit Care Med 154(6 Pt1): 1694-1699.

Stahel RA, Ginsberg R, Havermann K, Hirsch FR, Ihde DC, Jassem J, Karrer K, Maurer H, Osterlind K, Houtte P (1989) Staging and prognostic factors in small cell lung cancer: a consensus report. Lung Cancer 5: 119-126.

Stieber P, Dienemann H, Schalhorn A, Schmitt UM, Reinmiedl J, Hofmann K, Yamaguchi K (1999) Pro-gastrin-releasing peptide (ProGRP)-a useful marker in small cell lung carcinomas. Anticancer Res 19: 2673-2678.

Sunaga N, Tsuchiya S, Minato K, Watanabe S, Fueki N, Hoshino H, Makimoto T, Ishihara S, Saito R, Mori M (1999) Serum pro-gastrinreleasing peptide is a useful marker for treatment monitoring and survival in small-cell lung cancer. Oncology 57: 143-148.
Travis WD (2009) Lung tumors with neuroendocrine differentiation. Eur J Cancer 45(Suppl 1): 25-266.

Travis WD (2010) Advances in neuroendocrine lung tumors. Ann Oncol 21: vii65-vii71.

Wójcik E, Kulpa JK, Sas-Korczyńska B, Korzeniowski S, Jakubowicz J (2008) ProGRP and NSE in therapy monitoring in patients with small cell lung cancer. Anticancer Res 28(5B): 3027-3033.

Yamaguchi K, Aoyagi K, Urakami K, Fukutani T, Maki N, Yamamoto S, Otsubo K, Miyake Y, Kodama T (1995) Enzyme-linked immunosorbent assay of pro-gastrin-releasing peptide for small cell lung cancer patients in comparison with neuron-specific enolase measurement. Jpn J Cancer Res 86: 698-705.

Yang HJ, Gu Y, Chen C, Xu C, Bao YX (2011) Diagnostic value of pro-gastrinreleasing peptide for small cell lung cancer: a meta-analysis. Clin Chem Lab Med 49: 1039-1046.

This work is published under the standard license to publish agreement. After 12 months the work will become freely available and the license terms will switch to a Creative Commons AttributionNonCommercial-Share Alike 4.0 Unported License. 